\title{
Impediments to clinical diagnosis and management of juvenile-onset recurrent respiratory papillomatosis in Ilorin, Nigeria
}

\author{
Stephen Oluwatosin Adebola ${ }^{1 *}$, Adekunle David Dunmade ${ }^{2}$ \\ ${ }^{1}$ Department of Otorhinolaryngology, LAUTECH Teaching Hospital, Ogbomoso, Nigeria \\ ${ }^{2}$ Department of Otorhinolaryngology, University of Ilorin Teaching Hospital, Ilorin, Nigeria \\ Email: ${ }^{\text {tosinadebolang@yahoo.com }}$
}

Received 22 April 2013; revised 21 May 2013; accepted 30 May 2013

Copyright (C) 2013 Stephen Oluwatosin Adebola, Adekunle David Dunmade. This is an open access article distributed under the Creative Commons Attribution License, which permits unrestricted use, distribution, and reproduction in any medium, provided the original work is properly cited.

\begin{abstract}
Background: To report the impediments to the diagnosis and management of children with JuvenileOnset Recurrent Respiratory Papillomatosis as seen in a teaching hospital in West Africa. Methods: Retrospectively analysed study of participants requiring surgical intervention for histologically confirmed juvenile onset recurrent respiratory papillomatosis managed at the Department of Otorhinolaryngology, University of Ilorin Teaching Hospital, Ilorin over a 10year period (2002-2011) using prospectively collated database. Results: Juvenile-Onset Recurrent Respiratory Papillomatosis constituted $8.8 \%$ of 307 laryngeal pathologies seen during the study period. 18 (66.7\%) were males and 9 (33.3\%) females with a sex ratio (M:F) of 2:1. Age ranged from 1 year 4 months to 12 years with a mean age of 6.1 years $(S D=2.78)$, with the 6 - 10 age group constituting the largest categories in $\mathbf{5 1 . 9 \%}$ of patients seen. Patients from low socioeconomic class constituted slightly over half of the patients studied $(51.9 \%) .55 .5 \%$ of the patients presented late ( $>13$ months). All patients presented with hoarseness, stridor and difficulty in breathing. Misdiagnosis made by the referring clinician included Asthma, Laryngo-tracheo-bronchitis, Foreign body aspiration and Laryngomalacia. Involvement of the glottis occurred in $70.4 \%$ of cases seen, while bilateral involvement was present in $\mathbf{9 1 . 3 \%}$ of cases operated. Recurrence was seen in $63.0 \%$ of the patients and the best attendance at follow-up clinic was during the first three months post surgical extirpation. Emergency tracheostomy was done to relieve airway obstruction in 17 (63.0\%) patients. Conclusion: Impedi-
\end{abstract}

${ }^{*}$ Corresponding author. ments to diagnosis and management of JORRP are multifactorial. Misdiagnosis, late presentation and poor follow-up clinic attendance of patients with JORRP is still a common occurrence among the physicians. Recommendations on how to improve management and outcome of JORRP were made.

Keywords: Juvenile-Onset Recurrent Respiratory Papillomatosis; Paediatrics; Nigeria; Management

\section{INTRODUCTION}

Juvenile-Onset Recurrent Respiratory Papillomatosis (JORRP) is the most common benign neoplasm of the lanryngeal region amongst children. Virology studies have confirmed Human Papilloma Virus (HPV) types 6 and 11 as the cause [1,2]. The incidence reported in the USA was 4.3 per 100,000 children [3]. While a population based study of JORRP found an annual incidence of 0.24 per 100,000 per year in Canada [4]. However, the prevalence rate in sub-saharan Africa is not quite conclusive. Prevalence rates tend to vary with the presentation, country and socio-economic status of the population.

Although JORRP occurs in both children and adults [5], the most common variant occurs usually among the age group 5 - 15 years, hence the name juvenile [6] and it tends to be recurrent in nature and aggressive in character. Thus, JORRP remains an important differential of change in voice, stridor and difficulty with breathing in children. Other presenting symptoms of the condition include, cough, recurrent pneumonia, failure to thrive, dyspnea, dysphagia and acute respiratory distress and thus often confused with upper respiratory tract infection [5]. JORRP may also present as a life-threatening obstruction of the airway requiring emergency surgical in- 
tervention (tracheostomy) [7].

Juvenile Onset Recurrent Respiratory Papillomatosis is frequently misdiagnosed as Laryngotracheobronchitis, Asthma, Laryngomalacia or foreign body in the throat. While a diagnosis can be suspected from the clinical presentation, it needs to be confirmed radiologically, and histopathologically. Microlaryngoscopy and histopathological examination of the serially extirpated papillomata are common means of achieving this. While spontaneous remission of the condition is possible, recurrence remains a major challenge, hence the need for adjunctive treatment sometimes with immunotherapy. Extra-pulmonary spread to the entire aerodigestive tract and malignant transformation has been reported [8].

The key to a good outcome of management remains early diagnosis, proper and adequate management, and serial monitoring with follow-up. We observed that many of our patients with JORRP tended not to have good outcomes, which pose a challenge to us as caregivers. Therefore this study sets out to assess the impediments to diagnosis, and management of patients who presented with JORRP in a suburban tertiary hospital in NorthCentral Nigeria. This will assist in better management and improve the outcome in our patients.

\section{MATERIALS AND METHODS}

This was a retrospective descriptive study of patients who were managed for Juvenile-Onset Recurrent Respiratory Papillomatosis (JORRP) at the Department of Otorhinolaryngology, University of Ilorin Teaching Hospital, Ilorin over a 10-year period (2002-2011). The data of all patients who were managed for JORRP confirmed clinically, radiologically and histologically after surgical extirpation of the lesions were included in the study. In our centre, University of Ilorin Teaching Hospital, Ilorin, we manage laryngeal papillomatosis traditionally by surgical removal with rigid laryngoscopy (anterior commissure and broad view forms) aided with Hopkins telescope. Excluded from the study were patients whose case records were either not found or did not have complete information.

Data extracted from the case records included the socio-demographic characteristics including age, sex, parents social-economic class, (assessed after Oyedeji model) [9]. Clinical parameters included the main symptoms that patients presented with, duration of symptoms before presentation to the Otolaryngologist, previous presentations, previous diagnosis, mode of presentation (acuteemergency, or chronic), duration between presentation and surgical intervention.

The findings at investigations namely radiology, and at surgery (location and extent of papillomata) and histology were recorded. The type and number of surgical interventions that the patients had were also recorded.
The number of follow up visits, and outcome of the surgery especially considering clarity of the airway and voice were recorded. The number of patients that had recurrences within six months after surgical extirpation was noted.

The data was entered into the spreadsheet and analysed using the SPSS version 16.0 (Chicago, Illinois). The data was presented in simple descriptive forms as tables. Continuous variables were presented as decimals, with measures of central tendency and dispersions as Mean and standard deviations, while discrete variables were presented as proportions.

\section{RESULTS}

Juvenile-Onset Recurrent Respiratory Papillomatosis (JORRP) constituted $8.8 \%$ of a total 307 laryngeal pathologies seen during the study period at the University of Ilorin Teaching Hospital, Ilorin, Nigeria. Among the patients, $18(66.7 \%)$ were males and $9(33.3 \%)$ females with a sex ratio (M:F) of 2:1 (Table 1). The age ranged from 16 months to 12 years with a mean age of 6.1 years $(\mathrm{SD}=2.78)$, with the $6-10$ age group constituting the largest categories of patients seen, 14 (51.90\%), followed by 1 - 5 age group, 12 (44.40\%) (Table 1). Patients from low socioeconomic status (SE Classes IV and V) constituted about half of the patients studied, $51.9 \%$, while the middle (SE Class III) and upper socioeconomic strata (SE Class I and II) constituted $22.2 \%$ and $25.9 \%$ respectively.

The most common symptom to all patients were Hoarseness $(100 \%)$, stridor $(100 \%)$, difficulty with breathing $(100 \%)$, while $24(88.89 \%)$ presented with cough (Table 2). Patients that presented early $<13$ weeks constituted $44.5 \%$, while $55.5 \%$ presented late ( $\geq 13$ weeks). Two thirds of the patients, $66.7 \%$ had previously been on antibiotics and presented in the hospital after failure of the treatment. The diagnosis made by the referring clinician were varied, these include Asthma, Laryngo-tracheobronchitis, Foreign body aspiration and Laryngomalacia (Table 2). Majority of our patients (92.6\%) were delivered per vagina.

The larynx was the most affected part of the airway infiltrated with papillomata in our patients, which traversed its different sub-regions, with $70.4 \%$ involving the glottis, while transglottic involvement was seen in $14.8 \%$ (Table 3). Supraglottic and subglottic involvement accounted for $11.1 \%$ and $3.7 \%$ respectively. Out of the twenty three patients with either glottic or transglottic involvement, 91.3\% had bilateral vocal cord involvement, while $8.7 \%$ had unilateral involvement. Emergency tracheostomy was performed to relieve airway obstruction in $17(62.96 \%)$ patients. The six months recurrence rate post-surgical extirpation was $63.0 \%$, while $22.2 \%$ did not have recurrence during this period. However $14.8 \%$ were 
Table 1. Socio-demographic characteristics of the patients.

\begin{tabular}{lcc}
\hline & \multicolumn{2}{c}{ Participants } \\
\cline { 2 - 3 } & Frequency & Rcentages \\
\hline Age range (years) & $(\mathrm{n}=27)$ & $\%$ \\
1 - 5 & 12 & 44.4 \\
6 - 10 & 14 & 51.9 \\
11 - 15 & 1 & 3.7 \\
Mean + SD & $6.1 \pm 2.78$ & \\
Gender & & \\
Male & 18 & 66.7 \\
Female & 9 & 33.3 \\
Socioeconomic status (SES) & & \\
Class I & 3 & 11.1 \\
Class II & 4 & 22.2 \\
Class III & 6 & 37.1 \\
Class IV & 10 & 14.8 \\
Class V & 4 & \\
\hline
\end{tabular}

Note: SES Class I and II: Upper social class; SES Class III: Middle social class; SES Class IV and V: Lower social class.

lost to follow-up clinic visits. A large proportion of patients attended follow-up clinics within 1 to 3 months of surgical intervention (55.6\%), while $25.9 \%$ and $18.5 \%$ attended within 4 to 6 months and $\geq 7$ months respectively (Table 3). There were $2(11.8 \%)$ cases of difficult decannulation of the 17 patients tracheotomised, which is a complication of the tracheostomy done which was noted in the study.

\section{DISCUSSION}

Juvenile Onset Recurrent Respiratory Papillomatosis (JORRP) is benign in nature and is caused by Human Papillomavirus (HPV), types 6 and 11 [1,2], however due to the variability of its symptomatology, it is often misdiagnosed. Unfortunately, when diagnosis is made, it is more often than not delayed and eventual surgical treatment option is compounded with recurrence of the disease. Adjuvant therapies that have been investigated include dietary supplements, control of extra-oesophageal reflux disease, potent antiviral and chemotherapeutic agents and photo-dynamic therapies; although several have shown promise, none to date has cured the disease and some may even have serious adverse effects [5].

This study noted that laryngeal papillomatosis accounted for $8.8 \%$ of all laryngeal pathologies which were managed in our hospital during the ten year study period and the male to female ratio (M:F) was $2: 1$. This is simi-
Table 2. Clinical characteristics of the patients.

\begin{tabular}{|c|c|c|}
\hline \multirow{2}{*}{ Variable } & \multicolumn{2}{|c|}{ Participants } \\
\hline & Frequency & Percentages \\
\hline Main presenting symptoms & $(\mathrm{n}=27)$ & $\%$ \\
\hline Hoarseness & 27 & 100.0 \\
\hline Change in voice & 27 & 100.0 \\
\hline Upper airway obstruction & 27 & 100.0 \\
\hline Cough & 24 & 88.9 \\
\hline Failure to thrive & 6 & 25.9 \\
\hline \multicolumn{3}{|l|}{$\begin{array}{l}\text { Duration of symptoms before } \\
\text { index presentation (weeks) }\end{array}$} \\
\hline $0-4$ & 1 & 3.7 \\
\hline $5-12$ & 11 & 40.8 \\
\hline$\geq 13$ & 15 & 55.5 \\
\hline \multicolumn{3}{|l|}{$\begin{array}{l}\text { Previous diagnosis made by } \\
\text { referring physicians }\end{array}$} \\
\hline Laryngo-tracheo-bronchitis & 11 & 40.8 \\
\hline Asthma & 5 & 18.5 \\
\hline Respiratory papillomatosis & 4 & 14.8 \\
\hline Foreign body aspiration & 2 & 7.4 \\
\hline Laryngomalacia & 2 & 7.4 \\
\hline Airway obstruction? Cause & 1 & 3.7 \\
\hline Adenoids & 1 & 3.7 \\
\hline Acute bronchiolitis & 1 & 3.7 \\
\hline
\end{tabular}

lar to previous studies in Ibadan, Nigeria in which $6.69 \%$ of the laryngeal pathologies, managed over a fifteen (15) year period were due to laryngeal papillomatosis [10]. However, our findings were slightly higher but over a shorter period of 10 years. This underscores the fact that JORRP is a relatively common disease and might have even been under diagnosed. The finding of mean age of the patients being 6.1 ( $\mathrm{SD}=2.78)$, is within the age range of 5 to 15 years which was reported by previous studies [5]. We actually did not find any patient with age over fifteen years in this study. Although some other studies have found the peak presentation of JORRP to be $<5$ years of age [11]. Our study reported $44.4 \%$ of the patients seen as being $<5$ years of age.

JORRP remains a strong differential that must be considered in children with features of partial airway obstruction, presence of hoarseness and in the absence of fever. Despite the male preponderance reported in the study $(66.7 \%)$, other studies have not reported any sex predilection.

Patients from lower socioeconomic class (SES) IV and 
Table 3. Findings at surgery and post-surgery.

\begin{tabular}{|c|c|c|}
\hline & \multicolumn{2}{|c|}{ Participants } \\
\hline & Frequency & Percentages \\
\hline Glottic sub-site involvement & $\mathrm{n}=27$ & $(\%)$ \\
\hline Supraglottic & 3 & 11.1 \\
\hline Glottic & 19 & 70.4 \\
\hline Subglottic & 1 & 3.7 \\
\hline Transglottic & 4 & 14.8 \\
\hline \multicolumn{3}{|l|}{ Vocal cords involved } \\
\hline Single & 2 & 7.4 \\
\hline Both & 21 & 77.8 \\
\hline Not recorded & 4 & 14.8 \\
\hline \multicolumn{3}{|l|}{$\begin{array}{l}\text { Number of follow-up visits within } 6 \\
\text { months after discharge }\end{array}$} \\
\hline $1-3$ & 15 & 55.6 \\
\hline $4-6$ & 7 & 25.9 \\
\hline$\geq 7$ & 5 & 18.5 \\
\hline \multicolumn{3}{|l|}{$\begin{array}{l}\text { Recurrence within } 6 \text { months after } \\
\text { surgery }\end{array}$} \\
\hline Yes & 17 & 63.0 \\
\hline No & 6 & 22.2 \\
\hline Not known (lost to follow-up) & 4 & 14.8 \\
\hline
\end{tabular}

V constituted about half, $51.9 \%$ of the patients studied. There is documented evidence that socioeconomic status (SES) of the patients is a risk factor cervical cancer, whose aetiology has been linked with HPV [12]. This fact is mainly associated with the lower socioeconomic class who tend to be more sexually active and also more likely to have delay in accessing medical screening services. Hence due to the common aetiological agent of Human Papilloma Virus (HPV) especially types 6 and 11, a link between SES and JORRP has been postulated but not yet proven [13]. The study of Leung et al., despite having almost half of the patients with JORRP from lower SES, there was no correlation between SES and severity of the disease, JORRP [14]. Further research will need to be performed to clarify and elucidate this relationship.

Late presentation remains one of the impediments to proper management of JORRP found in this study, with about $55 \%$ presenting after 13 weeks of notice of symptoms. Late presentation may be attributable to both patients and physician factors. While many patients actually delayed in presenting to physicians, some others were actually misdiagnosed and thence were treated with various regimens of antibiotics, and were only referred appropriately when there were no appreciable improvements in symptoms, further delaying the presentation. Late presentation has been associated with difficulties in management, complications and poorer outcome of management [10].

The vast majority of our patients were delivered par vagina. Development of JORRP had been aetiologically linked to genital warts in the birth canal during the process of delivery $[15,16]$. While this history may be difficult to elicit in the mothers of our patients due to cultural reasons, it is advisable that all pregnant women be screened during antenatal care clinic, and those found with genital warts treated appropriately.

Only in $14.8 \%$ of the patients referred were the diagnosis of JORRP made and this is similar to other studies $[17,18]$. The role of continuing medical education especially concerning clinical symptoms, signs and recognition of diseases cannot be overemphasized.

While the symptoms of laryngeal papillomatosis are varied, all the patients in our study presented with hoarseness/change in voice, stridor and difficulty with breathing. Hence the presence of all 3 symptoms or at least 2 should immediately arouse the suspicion of a diagnosis of laryngeal papillomatosis in a child. The hallmark of the disease is the absence of fever. This can then be reaffirmed with radiologic investigations; especially by an X-ray of the soft tissue neck (particularly the lateral view) (Figure 1), the computerized tomography scan (CT scan) or a magnetic resonance imaging (MRI). Unfortunately, availability of a CT scan and MRI in our centre was not until towards the latter end of the study period and even then it was not affordable for the patients. Thus there is an impediment in terms of availability of equipment, for diagnosis. Despite this however, there has been reported restriction in the use of these facilities in the few centres in West African sub-region, where they were available due to costs that were not affordable to majority of the patients [19]. It is hoped that

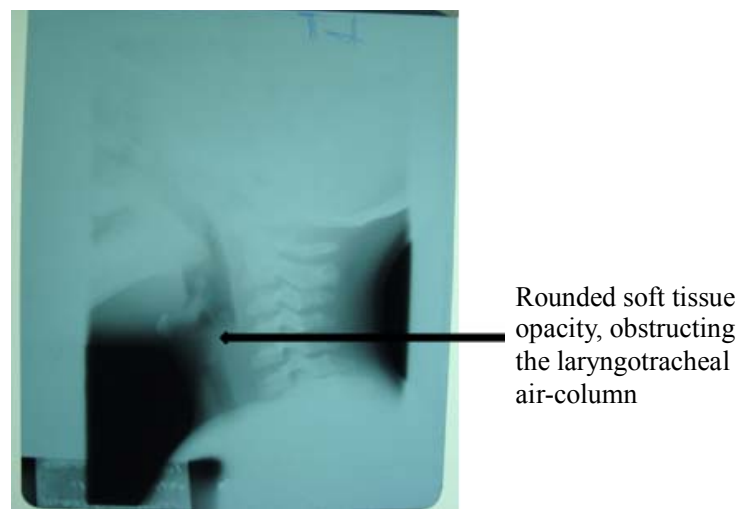

Figure 1. X-ray soft tissue neck (lateral view) of a patient with recurrent laryngeal papillomatosis. 
the emergence of the National Health Insurance Scheme (NHIS), will enhance availability and affordability of important equipment for medical diagnoses in Nigeria.

All participants had plain radiographs of the soft tissue of the neck which mostly revealed a soft tissue shadow located within the laryngeal air-column, with varying degrees of airway compromise. Our practice for surgical extirpation of recurrent papillomatosis involved the traditional surgical excision under direct laryngoscopy (anterior commissure and broad view forms) with the aid of Hopkins telescope to inspect the laryngeal inlet especially the sub-glottic region thoroughly (Figures 2 and 3). There is however a limitation to the view of the larynx by this equipment as compared with the microlaryngoscopy, which provides a better view and consequent better surgical clearance.

The use of microlaryngoscopy to aid in the complete removal of the papilloma cannot be overemphasized and this remains the best form of management of JORRP. This would avoid incomplete clearance which often results in recurrence. It involves the use of an operating microscope, which provides up to $350 / 400 \mathrm{~mm}$ lens magnification. There is a need for advocacy on the part of otolaryngologists, hospital administrators and the government, in ensuring the availability of this modality of treatment to aid favourable outcome. This is necessary for both specialists and specialist trainees.

The six months recurrence rate post-surgical extirpation was $63.0 \%$, while $22.2 \%$ did not have recurrence

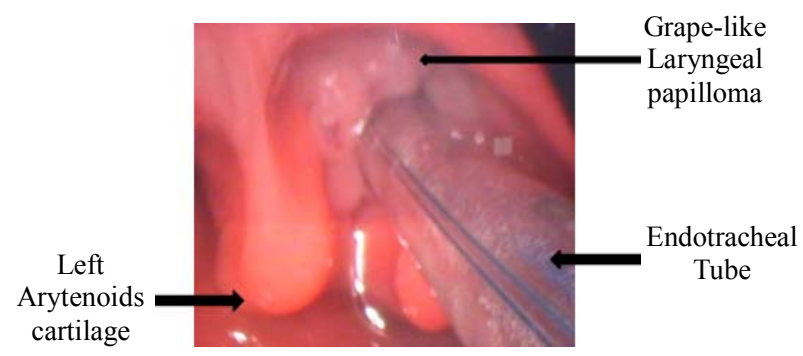

Figure 2. An endoscopic picture, showing laryngeal papillomata (pre-excision).

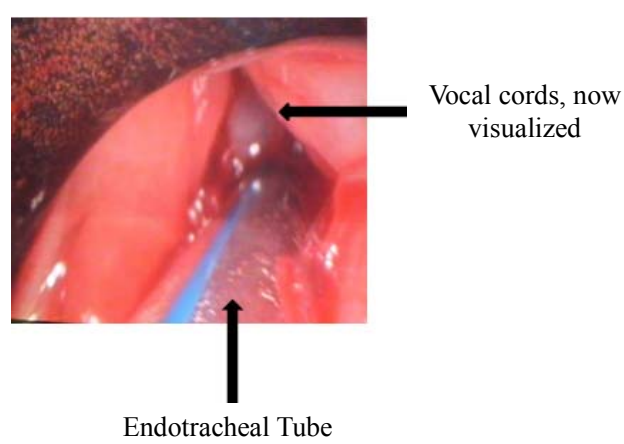

Figure 3. An endoscopic picture, showing laryngeal papillomata (post-excision). during this period. This rather high recurrence rate may be due to incomplete extirpation by an inexperienced surgeon, poor view and blind spots from suboptimal equipment leaving residual lesions, or frank recurrence of papillomata. Recurrent lesions create more serious management problems and are an impediment to a good outcome [5].

Emergency tracheostomy was done to relieve airway obstruction in $17(63.0 \%)$ patients as this is related to the severity of the cases and late presentation. This high tracheostomy rates are similar to other studies in West Africa [10], which unfortunately is as a result of late presentations. The morbidity of these patients increased with the use of tracheostomy because the procedure predisposes the papillomata that were hitherto within the airway to seep and infiltrate both the tracheostomy tract and stoma, encouraging recurrence. However, none of our patients had extra-laryngeal papilloma. Furthermore, previous tracheostomy has been found to be associated with difficult decannulation as was observed in $8.3 \%$ of our patients. Recurrence is common in the management of laryngeal papillomatosis especially in patients infected with HPV-11 [13]. Surgical excision techniques, including newer methods like the microdebrider, Carbon dioxide $\left(\mathrm{CO}_{2}\right)$ laser removal and endoscopic debridement have also been used to decrease the airway burden and improve voice quality. However, none of these to date has "cured" the condition. Hence it is not uncommon to have repeated surgical excision, even up to 3 to 5 times in a year with or without extra-laryngeal involvement as recurrence remains a major challenge in the management of recurrent laryngeal papillomatosis.

Other forms of medical and surgical treatment options have been described with varied success rates reported $[5,20,21]$. However, none of our patients had medical treatment and there was no mortality recorded in all the cases managed.

\section{CONCLUSIONS}

In conclusion, the impediments noted for the management of JORRP in this study were multifactorial; they include patients, physician, equipment, lesion as well as administrative factors. Hence, we recommend the following;

1) Early presentation of patients to the healthcare provider and prompt action instituted;

2) Higher suspicion from physicians, early referrals and appropriate management;

3) Avoidance of tracheostomy as much as possible, even though the challenge of imminent airway obstruction with late presentation is appreciated;

4) Provision of adequate and affordable equipment;

5) Health education, screening and adequate treatment 
of pregnant women with genital warts.

\section{ACKNOWLEDGEMENTS}

The authors acknowledge the contributions of Dr. A. O. Sogebi, Consultant Otolaryngologist, who proofread the manuscripts and made very useful contributions. Also, the Consultant Otolaryngologists in the Department of Otorhinolaryngology, University of Ilorin Teaching Hospital, whose patients were recruited for the study.

\section{REFERENCES}

[1] Terry, R.M., Lewis, F.A., Griffiths, S., Wells, M. and Bird, C.C. (1987) Demonstration of human papillomavirus type 6 and 11 in juvenile laryngeal papillomatosis by in-situ DNA hybridization. Journal of Pathology, 153, 245-248. doi:10.1002/path. 1711530308

[2] Zawadzka-Glos, L., Jakubowska, A., Chmielik, M., Bieliaka, A. and Brzewski, M. (2003) Lower airway papillomatosis in children. International Journal of Pediatric Otorhinolaryngology, 67, 1117-1121. doi:10.1016/S0165-5876(03)00191-5

[3] Larson, D.A. and Derkay, C.S. (2010) Epidemiology of recurrent respiratory papillomatosis. APMIS, 118, 450454. doi:10.1111/j.1600-0463.2010.02619.x

[4] Chadha, N.K. and James, A. (2010) Adjuvant antiviral therapy for recurrent respiratory papillomatosis. Cochrane Database of Systematic Reviews, Article ID: CD005053.

[5] Derkay, C.S. and Wiatrak, B. (2008) Recurrent respiretory papillomatosis: A review. Laryngoscope, 118, 12361247. doi:10.1097/MLG.0b013e31816a7135

[6] Derkay, C.S. (1995) Task force on recurrent respiratory papillomas. A preliminary report. Archives of Otolaryngology, Head and Neck Surgery, 121, 1386-1391. doi:10.1001/archotol.1995.01890120044008

[7] Snoeck, R., Wellens, W., Desloovere, C., Van Ranst, M., Naesens, L., De Clercq, E., et al. (1982) Treatment of severe laryngeal papillomatosis with intralesional injections of cidofovir [(S)-1-(3-hydroxyl-2-phosphonylmethoxypropyl) cytosine]. Journal of Medical Virology, 79, 54255429.

[8] Stamataki, S., Nikolopoulos, T.P., Korres, S., Felekis, D., Tzangaroulakis, A. and Ferekidis, E. (2007) Juvenile recurrent respiratory papillomatosis: Still a mystery disease with difficult management. Head \& Neck, 29, 155-162. doi:10.1002/hed.20491

[9] Oyedeji, G.A. (1985) Socio-economic and cultural background of hospitalized children in Ilesha. Nigerian Journal of Paediatrics, 12, 111-117.

[10] Fasunla, A.J. and Lasisi, O.A. (2009) Diagnostic challenges of laryngeal papillomatosis and its implications among children in developing country. International Journal of Pediatric Otorhinolaryngology, 73, 593-595. doi:10.1016/j.ijporl.2008.12.009

[11] Shykhon, M., Kuo, M. and Pearman, K. (2002) Recurrent respiratory papillomatosis. Clinical Otolaryngology and Applied Sciences, 27, 237-243.

[12] Parikh, S., Brennan, P. and Boffetta, P. (2003) Meta-analysis of social inequality and the risk of cervical cancer. International Journal of Cancer, 105, 687-691. doi:10.1002/ijc.11141

[13] Wiatrak, B.J., Wiatrak, D.W., Broker, T.R. and Lewis, L. (2004) Recurrent respiratory papillomatosis: A longitudinal study comparing severity associated with human papilloma viral types 6 and 11 and other risk factors in a large pediatric population. Laryngoscope, 114, 1-23. doi:10.1097/01.mlg.000148224.83491.0f

[14] Leung, R., Hawkes, M. and Campisi, P. (2007) Severity of juvenile onset recurrent respiratory papillomatosis is not associated with socioeconomic status in a setting of universal health care. International Journal of Pediatric Otorhinolaryngology, 71, 965-972. doi:10.1016/j.ijporl.2007.03.009

[15] Gissmann, L., Diehl, V., Schultz-Coulon, H.-J. and zur Hansen, H. (1982) Molecular cloning and characterization of human papillomavirus DNA derived from a laryngeal papilloma. Journal of Virology, 44, 393-400.

[16] Silverberg, M.J., Thorsen, P., Lindeberg, H., Grant, L. and Shah, K.V. (2003) Condyloma in pregnancy is strongly predictive of juvenile-onset recurrent respiratory papillomatosis. Obstetrics \& Gynecology, 101, 645-652. doi:10.1016/S0029-7844(02)03081-8

[17] Coope, G. and Connett, G. (2006) Juvenile laryngeal papillomatosis. Primary Care Respiratory Journal, 15, 125127. doi:10.1016/j.pcrj.2006.02.004

[18] Zacharisen, M.C. and Conley, S.F. (2006) Recurrent respiratory papillomatosis in children: Masquerader of common respiratory diseases. Pediatrics, 118, 1925-1931. doi:10.1542/peds.2006-1555

[19] Olaosun, A.O., Bello, T.O., Aremu, A.A., Sogebi, O.A. and Tobih, J.E. (2007) The hypoplastic maxillary antrum: A pitfall for the unwary. The Internet Journal of Otorhinolaryngology, 6. doi:10.5580/10df

[20] Pasquale, K., Wiatrak, B., Woolley, A. and Lewis, L. (2003) Microdebrider versus $\mathrm{CO}_{2}$ laser removal of recurrent respiratory papillomas: A prospective analysis. $\mathrm{La}$ ryngoscope, 113, 139-143. doi:10.1097/00005537-200301000-00026

[21] Ilmrinen, T., Nissila, H., Rihkanen, H., Roine, R., Pietarinen-Runtti, P., Pitkaranta, A. and Aaltonen, L. (2011) Clinical features, health-related quality of life, and adult voice in juvenile-onset recurrent respiratory papillomatosis. Laryngoscope, 121, 846-851. 